\title{
El nacimiento de la Administración pública regulatoria en Perúl
}

\author{
Orlando Vignolo Cueva ${ }^{2}$
}

\section{RESUMEN}

La liberalización peruana de inicios de los años noventa, apoyada en el influjo fundamental del principio de subsidiariedad horizontal, produjo no sólo cambios prestacionales y normativos en sectores económicos (con la consecuente reducción del Estado prestador), sino que también supuso la creación de una nueva estructura organizativa administrativa que sirva y se acomode a ciertas características de unas aparentes "nuevas" potestades regulatorias. Desde una versión más estricta y ejecutiva, estas estructuras comportan una adaptación de la policía administrativa y otras competencias administrativas que modulan una intervención sobre estos sectores económicos liberalizados. El presente trabajo intenta desentrañar mitos y certezas jurídicas sobre el surgimiento de esta fórmula organizativa cercana a cumplir veintiséis años de existencia.

1 El presente trabajo constituye una entrega de la investigación adelantada en el marco de la tesis doctoral defendida por el suscrito en la Facultad de Derecho de la Universidad de Zaragoza, España, durante el mes de junio pasado. En los siguientes meses aparecerá una publicación completa de esta investigación doctoral, reflexionada desde y para el derecho peruano, en la que se analizará el principio de subsidiariedad en su vertiente social y su relación con la liberalización de sectores y el propio surgimiento de las organizaciones regulatorias.

2 Doctor en Derecho la Universidad de Zaragoza, Zaragoza, España. Profesor de la Universidad de Piura, Piura, Perú. Director de la Revista Anuario de la Función Pública. Abogado del Estudio Echecopar, Lima, Perú. Correo electrónico: orlandovignolo@yahoo.com. Fecha de recepción: 27 de septiembre de 2017. Fecha de modificación: 20 de octubre de 2017. Fecha de aceptación: 30 de octubre de 2017. Para citar el artículo: VignOlo CuEvas, ORLANDO, "El nacimiento de la Administración pública regulatoria en Perú", Revista digital de Derecho Administrativo, Universidad Externado de Colombia, n. ${ }^{\circ}$ 19, 2018, pp. 83-117. DOI: https://doi.org/10.18601/21452946.n19.06 
Palabras claves: Liberalización, Organización regulatoria, Potestad administrativa, Regulación.

\title{
The Origins of Regulatory Agencies in Peru
}

\begin{abstract}
Peruvian liberalization of economic activities in the early 1990s, supported by the influence of the principle of horizontal subsidiarity, not only produced important changes in regulations and in the performance of certain industries (with the ensuing decline of the welfare State), but also lead to a new form of administrative organization composed by agencies invested with regulatory powers. From a more narrowed and executive perspective, these regulatory bodies encompass an adaptation of the administrative oversight and other forms of intervention in the liberalized industries. This paper attempts to unravel myths and legal certainties on the emergence of the Peruvian regulatory organization on the verge of its twenty-six anniversary.
\end{abstract}

Keywords: Liberalization of Economic Activities, Regulatory Organization, Regulatory Agencies, Rulemaking Authority, Welfare State.

\section{INTRODUCCIÓN}

El análisis jurídico-administrativo de la puesta en marcha de los organismos reguladores siempre permitirá cerrar el estudio del proceso peruano de la liberalización, este último tan poco asumido y analizado en la doctrina nacional. Aunque vale aclarar que estas nuevas administraciones públicas fueron asumidas por muchos países de Sudamérica siguiendo el modelo de las agencias reguladoras norteamericanas, en un marco temporal similar al nacimiento de las comisiones reguladoras independientes españolas ${ }^{3}$. En el caso peruano, su origen tiene un dato específico, se produjo bajo una importante cobertura de la subsidiariedad social en el sentido que este principio permitió justificar para ciertos ámbitos complejos la necesidad de contar con nuevas entidades administrativas que, desde datos organizativos y funcionales diferentes, y con un régimen propio, pudieran afrontar las disfuncionalidades de las libertades

3 Eduardo Virgala ForURia, "Agencias (y agencias reguladoras) en la comunidad europea", Revista de Derecho Constitucional Europeo, n. ${ }^{\circ}$ 05, Sevilla: Instituto Andaluz de Administración Pública, 2006. 
(económicas) y el mantenimiento de un nuevo orden entre agentes y participantes de diversas naturalezas (usuarios, prestadores e intervinientes diversos) ${ }^{4}$.

En síntesis, la liberalización ha producido no sólo cambios prestacionales normativos en sectores, sino también supuso la creación de una nueva estructura organizativa administrativa ${ }^{5}$ que sirva y se acomode a ciertas características de las "novedosas" potestades regulatorias ${ }^{6}$, las cuales - desde una versión más estricta y ejecutiva-comportan, incluso con algunas innovaciones de más reciente data, "la utilización de poderes de distinta naturaleza: normativos, de control y supervisión, arbitrales y sancionadores"7.

En ese sentido, estas organizaciones administrativas son creadas por el legislador peruano ${ }^{8}$ como una modalidad apartada de las verdaderas AAI, destinadas a desenvolverse principalmente en sectores de fuerte incidencia económica, siempre con una característica fundamental que las identifica: su relativa y variada autonomía (de la que daremos cuenta luego)9 ${ }^{9}$, condición de protección organizativa que le permite responder de mejor manera a dos propósitos principales de interés público. Por un lado, garantizar la prestación o suministro efectivo de los diversos servicios que están bajo su competencia por parte de los operadores (con características de habitualidad, continuidad, universalidad y calidad en la cobertura a favor del conjunto de los ciudadanos ${ }^{10}$. En segundo término, afrontar el objetivo de revisar y resolver los reclamos de los usuarios del servicio por prestaciones defectuosas o incumplimiento de contratos de concesión (o surgidos de los títulos habilitantes de los prestadores).

En cualquier caso, son entidades administrativas que desde siempre aparecieron conformadas como separadas de manera relativa del Gobierno, los políticos y otras fórmulas diversas de sujeción, por lo tanto, aisladas y prote-

4 La relación entre ciertos derechos económicos, la subsidiariedad y otros principios rectores de la economía es muy estrecha. Así, el profesor Betancor reconoce que muchos de estos últimos son "derechos fundamentales que incorporan en su contenido los principios rectores de la política social y económica: ejemplo de la integración armónica". Ver esta cita Andrés Betancor Rodríguez, Regulación, mito y derecho: Desmontando el mito para controlar la intervención de los reguladores económicos, Madrid: Civitas, 2010, p. 126.

5 Manuel Aragón Reyes, "Del Estado intervencionista al Estado regulador", Tratado de regulación del sector eléctrico, vol. 1, Cizur Menor: Aranzandi, 2009, p. 45.

6 Ver estas cuestiones iniciales sobre las organizaciones regulatorias en: ANDRÉs BETANCOR RODRíGuEZ, Regulación, mito y derecho: Desmontando el mito para controlar la intervención de los reguladores económicos, Madrid: Civitas, 2010, p. 313.

7 José Laguna de PaZ, , Derecho administrativo económico, Navarra: Thomson-Reuters, 2016, p. 33.

8 Eduardo Virgala ForuRIa, "Agencias (y agencias reguladoras) en la comunidad europea", Revista de Derecho Constitucional Europeo, n. ${ }^{\circ}$ 05, Sevilla: Instituto Andaluz de Administración Pública, 2006.

9 Andrés BetanCor RodríGuez, op. cit., p. 314.

10 María Yolanda Fernández García, Estatuto jurídico de los servicios esenciales económicos en red, Madrid-Buenos Aires: Ciudad Argentina-INAP, 2003.p. 70. 
gidas frente a la partidarización y cualquier elemento propio de la jerarquía o rectoría ${ }^{11}$ respecto de otras administraciones públicas.

Lo anterior no debe confundirse con la figura organizativa de la adscripción que el legislador peruano siempre recoge y reconoce como concepto en las respectivas normas de creación de estos reguladores, a fin de unirlos por afinidad funcional a un ministerio y al propio Consejo de Ministros ${ }^{12}$. Tampoco puede confundirse con una pérdida de autonomía de esta administración pública, si es que aparece en una determinada materia o sector de actuación, compartiendo potestades con otras que no gozan de sus presupuestos de protección, pues como bien lo afirmó Betancor la pérdida de este presupuesto

11 El concepto de rectoría que aparece reconocido en varias normas de organización administrativas peruanas debe ser entendido como una competencia de dirección y ordenación muy extensa recaída sobre un determinado sector de actuación a favor de una administración pública específica. En cualquier caso, esta potestad administrativa debe respetar la división territorial del poder instrumentalizada mediante la descentralización preceptuada por nuestra Constitución. Ahora bien, la rectoría incluiría principalmente en cabeza de una organización administrativa, las siguientes funciones: i) la capacidad de reglamentar con alcance nacional, ii) de colocar bases de actuación y de práctica de potestades parajudiciales para eliminar controversias y presentar criterios uniformes sobre materias controvertidas (a partir de un órgano decisor, pero que siempre quedaría sometido a la presunción iuris tamtun de legalidad aplicable a sus respectivos actos administrativos), iii) el ejercicio de ciertas potestades ejecutivas (para formular políticas públicas únicas pero con un cierto margen de adaptabilidad y adecuadas a la citada autonomía de determinas entidades que comparten roles en la materia), y iv) finalmente, de preparación y formulación de los correspondientes procedimientos que instrumentalizarán las potestades de todos las administraciones públicas intervinientes en la materia correspondiente. Como se notará es un concepto macro, muy de origen peruano, aunque tiene algunos rasgos cercanos a la Constitución mexicana pero entendido en otra perspectiva organizativa, económica y adaptable al federalismo imperante en ese último país (ver el artículo 25 de la Constitución Mexicana).

12 La adscripción es un mecanismo o técnica de medida que trata de afirmar la responsabilidad política ante el Congreso de la República de un ministro respecto de organizaciones administrativas diversas y sobre las que existe una afinidad material y competencial con el ministerio bajo su mando (por eso la adscripción se refiere a un sector de actuación). No es una noción de jerarquía ni de vinculación sujetoria de una entidad administrativa frente a otra. En el derecho peruano, el presidente del Consejo de Ministros responde generalmente por diversos organismos funcionalmente heterogéneos pero adscritos a la Presidencia del Consejo de Ministros, mientras los demás ministros responden de manera más homogénea por entidades funcionalmente más cercanas al correspondiente ministerio al que le correspondiente mandar. Debe entenderse que la administración pública peruana del Estado se ha venido organizando en sus relaciones con el Parlamento mediante este instituto introducido al país desde 1963 con la antigua Ley del Presupuesto Funcional, no existiendo mayores datos para temer o alegar una posible afectación de la autonomía relativa de los reguladores, a partir de su aplicación efectiva y frecuente. Finalmente, este elemento aparece actualmente reconocido de manera única para todos los organismos reguladores, indicándose que quedan adscritos a la Presidencia del Consejo de Ministros (ver el artículo 32 de la LOPE). 
no quiere decir que el regulador tenga el monopolio de la ordenación de un mercado o sector económico determinado. El regulador independiente está inserto en un sistema de regulación de dicho sector en el que las potestades administrativas de intervención, control o supervisión están compartidas con otras autoridades administrativas que no responden a esa característica organizativa ${ }^{13}$.

Por otro lado es necesario precisar que estos "entes administrativos" utilizaron varias denominaciones en diferentes países ${ }^{14}$, no existiendo hasta la fecha un consenso sobre su nomen iuris. Así por ejemplo se denominan agencias en el mundo anglosajón ${ }^{15}$, autoridades administrativas en Italia y/o autoridades administrativas independientes en Francia y España, u organismos reguladores en nuestro país. Frente a esta terminología tan heterogénea he considerado conveniente utilizar el nombre de organismos reguladores, dejando de lado al término ajeno de $\mathrm{AAI}^{16} \mathrm{u}$ otros. En cualquier caso esta denominación considero es posible de ser generalizada en el derecho peruano y su aplicación paritaria debe darse ante la desordenada legislación sectorial, a partir del reconocimiento actual hecho por el legislador peruano (según se explicará a continuación).

Sin embargo, a pesar de disparidad en las nomenclaturas en varias realidades, lo cierto es que la característica común de este tipo de administraciones públicas es que nacen a la par de acontecimientos económicos, políticos y jurídicos propios de la liberalización ${ }^{17}$. Por ejemplo en España, esta organización administrativa aparece en 1994 con la Ley de ordenación del sistema eléctrico nacional (LOSEN), Ley 40/1994, que crea la primera Comisión Reguladora Española en la Electricidad (CSEN), lo que más adelante sería la Comisión

13 Andrés Betancor Rodríguez, op. cit., p. 314.

14 Manuel Aragón Reyes, op. cit., p. 45.

15 En sentidos terminológico y organizativo, utilizar las palabras "comisión" y "agencia" es lo mismo, teniendo ambas un claro origen norteamericano.

16 Las administraciones públicas independientes, según definición que es perfectamente trasladable a nuestro derecho, son "organizaciones administrativas de carácter institucional no representativas, que desarrollan funciones propias de la Administración activa y que están configuradas legalmente de forma que el Gobierno y el resto de la Administración gubernativa carecen de las facultades de dirección que configuran típicamente su relación con la Administración institucional instrumental, y ello con la finalidad de neutralizar políticamente una actividad integrada en la órbita del Poder Ejecutivo". Ver esta cita en el interesante libro de Mariano Magide HeRrero, Límites constitucionales de las administraciones independientes, Madrid: INAP, 2000. p. 33. Esta categoría es asumida en el derecho peruano por el profesor Abruña indicando que sólo quedan incluidas en esta clasificación el "Jurado Nacional de Elecciones, el Banco Central de Reserva en el ejercicio de sus funciones específicas y la Superintendencia de Bancas y Seguros". Antonio Abruña PuYOL, Delimitación jurídica de la administración pública en el ordenamiento peruano, Lima: Palestra, 2010, p. 186.

17 Ver reflexión preliminar de Fernández Ordóñez en la obra de Miguel Ángel LaSHERAS, La regulación económica de los servicios públicos, Barcelona: Editorial Ariel, 1999, p. 5. 
Nacional de la Energía (CNE) ${ }^{18}$. Luego, continúa en 1996 con la expedición del Real Decreto-Ley 6/1996, del 7 de junio, de Liberalización de las Telecomunicaciones, que creó la Comisión del Mercado de las Telecomunicaciones (CMT).

A su turno, en Perú se originaron a partir de 1991 en medio de la denominada "Reforma y modernización del Estado"19 , proceso amplio que implicó la reducción estatal a una mínima expresión y la implantación -en general- de muchísima flexibilidad en la gestión de las organizaciones administrativas (incluso con la introducción poco técnica del derecho privado). Esta reducción y retirada del Estado abrió paso a la entrada y competencia de nuevos operadores en varios sectores (despublificados) ${ }^{20}$ y el correspondiente reacomodo de las nacientes administraciones públicas bajo la cláusula del Estado regulador ${ }^{21}$.

18 La CNE nació por la Ley 34/1998, del 7 de octubre, de Sector de Hidrocarburos, y luego fue desarrollado por el Real Decreto 1339/1999, del 31 de julio, que aprobó su Reglamento.

19 Esta expresión normativa presentada en el párrafo principal identificó a varios procesos de reforma administrativa iniciados por distintos gobiernos peruanos. El primero de ellos fue establecido por el expresidente Fujimori durante su primer periodo de gestión. Entre los distintos lineamientos que guiaron este proceso resaltaron: a) el establecimiento de un programa de renuncias voluntarias de empleados públicos y personal de empresas estatales, bajo incentivos económicos; b) la reorganización y creación de entidades cuyas funciones resultaban importantes para el éxito del programa económico del gobierno. Bajo este lineamiento apareció la administración tributaria y aduanera (SUNAT), el primer regulador denominado OSIPTEL (1991), el famoso INDECOPI (1992) y el segundo regulador denominado SUNASS (1992), y por último, c) la reorganización de la administración pública en general.

Posteriormente aparece un segundo intento hacia 1995 bajo el mismo gobierno fujimorista. En este periodo se creó el tercer regulador denominado OSINERG (1996) y dos años después aparece el cuarto regulador llamado OSITRAN (1998). Un tercer momento fue la llamada modernización del Estado peruano planteada mediante la Ley n. ${ }^{\circ} 27.658$, norma que a lo largo de sus cuatro capítulos y quince artículos buscaba la obtención de mayores niveles de eficiencia del aparato estatal y una participación más directa de la Presidencia del Consejo de Ministros en este proceso. Para una revisión profunda de estos procesos de reforma puede revisarse la obra de CARLES RAMIÓ MATAS, La fortaleza institucional de las agencias reguladoras de América Latina. Especial referencia a los casos del Perú y de Republica Dominicana, Granada: UIM, 2008, pp. 60-63.

20 Elisenda Malaret GarCia, "Administración pública y regulación económica", La autonomía municipal, administración y regulación económica, títulos académicos y profesionales, Cizur MenorNavarra: Thomsom-Aranzadi, 2007, p. 757.

21 Desde las ciencias de la administración el profesor Ramió Matas señalaba que estos procesos de implantación del Estado regulador parten "de la base de un proceso de reingeniería organizativa orientando a mejorar la eficiencia y eficacia de los aparatos públicos convencionales, con eficiencia y eficacia orientados a obtener una moderna gestión pública. Y por otra parte, de la necesidad de regular con eficiencia y neutralidad política (es decir con autonomía e independencia) numerosos sectores económicos y sociales generándose un proceso de centralidad combinada entre los agentes públicos y el mercado". CARLES RAMIÓ MATAS, La fortaleza institucional de las agencias reguladoras de América Latina. Especial referencia a los casos del Perú y de Republica Dominicana, Granada: UIM, 2008. 
En suma, es claro que la inclusión del Estado regulador permitió buena parte de la adaptación pública en los años iniciales de nuestra liberalización, a partir de las potestades que se habilitaron a las nuevas entidades regulatorias, siempre en la búsqueda de los dos propósitos antes mencionados y de corregir ineficiencias, desventajas y limitar asimetrías informativas. Sin perjuicio de esto, el Estado regulador también aseguró que estos nuevos desempeños administrativos se efectuaran de manera más acorde a los mercados abiertos (pero sin que los últimos -a veces- dejen de ser intensamente intervenidos), en el que se permita la inclusión, participación y entrada de más operadores y agentes económicos. En suma, la cláusula del Estado regulador aunque pareciera ser una novedad de la liberalización no renovó nuestra "arquitectura administrativa"22 (aunque sí permitió el alumbramiento de un derecho administrativo peruano mucho más serio y científico), siendo correcto afirmar que fue un ajuste de los viejos paradigmas con ciertas nuevas fórmulas de intervención administrativa.

\section{ANTECEDENTES Y NACIMIENTO DE LOS ORGANISMOS REGULADORES PERUANOS}

Además del propio proceso de liberalización de los noventa, lo cierto es que las transiciones políticas en América Latina ayudaron mucho al nacimiento de las organizaciones regulatorias en esta parte del mundo occidenta ${ }^{23}$, pues dieron el marco perfecto para cumplir con las exigencias ciudadanas de creación de entes neutrales, permitir y asegurar el ingreso y participación de operadores económicos privados (inversión extranjera directa), y además originar un sistema mínimo de institucionalidad y gobernanza. En ese sentido, este antecedente histórico también resultó decisivo para nuestro país, no sólo para permitir un retroceso de la presencia estatal en los sectores productivos y de servicios, sino porque frenó los largos procesos de nacionalizaciones confiscatorias ${ }^{24}$ que llevó

22 Ver esta gráfica frase en la obra de José LAGUNA DE PAZ, Derecho administrativo económico, Navarra: Thomson-Reuters, 2016, p. 34.

23 La primera transición democrática frente al largo periodo de dictaduras vivido por Latinoamérica comenzó en Republica Dominicana (1978) y fue seguida luego por Ecuador (1979), Bolivia (1982), Argentina (1983), Nicaragua (1984), Brasil y Uruguay (1985), Guatemala (1986), Chile (1990), El Salvador (1992), Honduras y Panamá (1994).

24 El largo periodo de la dictadura militar (1968-1980) es una época a ser estudiada por el actual derecho administrativo peruano, pues mucho de lo realizado en esa etapa impactó en varios de los contenidos de los institutos que hasta ahora utilizamos. Por ejemplo, la expropiación forzosa y varias de sus deficiencias tienen que ver con las anómalas construcciones que se usaron en esa época. En este periodo, las nacionalizaciones de diversos bienes y servicios no tenían una compensación real, inmediata y efectiva a favor de los privados. Al menos, esto puede predicarse de la entrega de los llamados "bonos de la deuda agraria", tanto que estos fueron considerados por el actual TCP como un elemento "no cancelatorio" por su propia entrega o tenencia (entonces fueron medios que atentaron 
adelante la dictadura militar anterior a la Constitución de 1979 y que tuvo no pocos intentos y reflejos en la segunda parte de la década de los ochenta.

Este panorama sombrío cambió en los primeros años de los noventa, a partir de que el país se embarcara en un programa de estabilización económica e inserción en escenarios internacionales aunado a una reforma estructural que incluía el citado y desordenado programa de privatización de empresas estatales. De este modo se eliminaron las restricciones a la inversión extranjera, impulsó la desregulación, la neo-regulación y la lucha frontal contra el estatismo imperante en las épocas iniciales de la liberalización ${ }^{25}$.

El contexto del nacimiento de los llamados organismos reguladores en el Perú se da en medio de estos procesos, incluso con anterioridad, de desmonopolización y pulverización de la iniciativa estatal en las telecomunicaciones, pero siempre al amparo de la liberalización emprendida antes de la promulgación de la $\mathrm{CP}^{26}$. Así pueden establecerse tres etapas claramente marcadas: i) la primera, iniciada a mediados de 1991 hasta 1998 que aparece normativamente dispersa y con menos dosis de autonomía para los recién creados; ii) una segunda, a partir del año 2000 hasta 2005, época en la que se consolida el desarrollo de estas entidades administrativas (a partir de la promulgación de la Ley N. ${ }^{\circ} 27.332$ ) y en la que también aparecen otras organizaciones administrativas que tienen componentes organizacionales y funcionales cercanos a los iniciales reguladores. Esta etapa puede considerarse como la de reforzamiento institucional, paridad de tratamiento y eliminación de la dispersión con la que surgieron al inicio de la ola liberalizadora, $\mathrm{y}_{;}$finalmente, iii) el tercer periodo entre el año 2007 y 2009 que estuvo marcada por la expedición de la LOPE, la cual ha fijado mecanismos y condiciones para que se creen nuevos reguladores,

contra la garantía patrimonial de los afectados). Ver, entre muchas otras, la STCP, recaída en el Exp. 0022-1996-PI/TC, 16 de julio de 2013, FJ. 14.

25 Lorena Alcazar Y Pierina Pollarolo, "La regulación y el manejo de controversias de los sectores de telecomunicaciones y electricidad: Un análisis institucional comparativo", Documento de trabajo N. ${ }^{\circ}$, Lima: Instituto Apoyo, 2000, p. 15.

26 Durante esta época inicial de la liberalización ocurre también la creación del INDECOPI mediante Ley $\mathrm{N}^{\circ} 25.868$ de noviembre del 1992, apareciendo configurado como un organismo público descentralizado adscrito a la Presidencia del Consejo de Ministros. Esta figura organizativa (de plena originalidad del legislador de la época) hasta ahora se sigue reconociendo como una especie de nuestra "descentralización funcional", que permite a la entidad "descentralizada" algunos niveles de autonomía y su creación legislativa mediante el uso de la técnica fundacional. Ver estas cuestiones en Jesús Caballero Ortiz, "La descentralización funcional", Revista de Derecho Público, n. ${ }^{\circ}$ 8, Caracas: Editorial Jurídica Venezolana, 1981, p. 7.

Por otro lado, el INDECOPI nació para promover el desarrollo de las libertades en la economía peruana, la leal y honesta competencia, así como para garantizar que los diversos mercados funcionen adecuadamente mediante libre concurrencia y protección de los consumidores, haciendo una suerte de árbitro general, aunque sin los niveles de autonomía con los que nacieron los organismos reguladores. 
aunque muchas veces se les reconozca con otros nombres (principalmente con la denominación de superintendencias y bajo la subcategoría de "organismos técnicos especializados").

En este capítulo me ocuparé principalmente de la primera parte, tal como indica el título, sin embargo dado que se tratan de hechos separados sólo por la evolución legislativa aplicable a estas entidades administrativas, en algunas explicaciones introduciré las explicaciones sobre la segunda y tercera fase (esta última con datos más restringidos).

En primer término, como bien afirma DANOS, para el caso peruano no puede considerarse que estas organizaciones administrativas se concentraron sólo en espacios prestacionales, su irrupción se dio también en ciertos aspectos concesionales con otras justificaciones de corte económico y para controlar ejecuciones contractuales, puesto que la creación de los

organismos reguladores de los servicios públicos (telecomunicaciones, electricidad, saneamiento) y de las concesiones de obras públicas de infraestructura de transporte (puertos, aeropuertos, carreteras, vías ferroviarias) claramente inspirados en los modelos de los países anglosajones, con el objeto de garantizar un tratamiento técnico de la regulación y supervisión de las actividades económicas calificadas como servicios públicos, o que se desarrollan en condiciones de monopolio natural o poco competitivas y las que requieren para su desarrollo la utilización de redes e infraestructuras ${ }^{27}$.

En el mismo sentido, también cabe reconocer que las cuatro iniciales organizaciones regulatorias no fueron planificadas en sus creaciones con un sólo criterio (de anterioridad o posterioridad a la aplicación de la correspondiente técnica aparecida en la liberalización). Por ejemplo el primer ámbito donde aparecieron (el OSIPTEL para el sector de telecomunicaciones) ocurrió en noviembre del año 1991 antes de la venta de la compañía peruana de teléfonos (СРT) que prestaba el servicio para la ciudad de Lima Metropolitana y de la propia empresa nacional de telecomunicaciones (ENTEL), que operaba en el resto del territorio peruano ${ }^{28}$. Los otros tres aparecieron después de manera

27 Jorge Danos Ordóñez, "Los organismos reguladores de los servicios públicos en el Perú", Revista Peruana de Derecho de la Empresa, n. ${ }^{\circ} 45$, Lima: Asesorandina, 2000. p. 60.

28 El texto original del artículo 79 del Decreto Legislativo n. ${ }^{\circ} 702$, norma dada dentro del paquete liberalizador y que debe ser catalogada como un instrumento más de neo-regulación, preceptuaba el origen del primer regulador peruano en los siguientes términos: "La Comisión Reguladora de Tarifas de Comunicaciones, que en adelante se denominará 'Organismo Supervisor de Inversión Privada en Telecomunicaciones', se encargará de garantizar la calidad y eficiencia del servicio brindado al usuario y de regular el equilibrio de las tarifas". 
desordenada ${ }^{29}$, incluso fuera de la privatización o como parte de los procesos de reforma estatal emprendidos por el Gobierno fujimorista ${ }^{30}$. Así el OSITRAN surge

en fecha previa al inicio del proceso de otorgamiento de concesiones de infraestructura de transporte de uso público. En cambio, OSINERG fue creado años después del inicio del proceso de transferencia de la propiedad de empresas estatales y del establecimiento del nuevo marco regulador del sector. El caso de SunASS es especial porque se trata de un organismo que fue creado en el marco del proceso de reestructuración del sector, saneamiento desarrollado durante los primeros años de la década pasada, por el cual los servicios de agua potable y alcantarillado que eran de responsabilidad de una empresa estatal nacional (SENAPA) fueron transferidos a las municipalidades provinciales y distritales, con excepción de la empresa de saneamiento de Lima-Callao (SEDAPAL) que mantiene su calidad de empresa del gobierno nacional ${ }^{31}$.

Es claro que estos dos ámbitos enlazados al ingreso de los privados en ciertos desmonopolizados servicios (con la anterior o consecuente privatización de las correspondientes empresas estatales que dejaron estos sectores) y, en segundo lugar, la inclusión de nuevas iniciativas en las infraestructuras en red

29 Los otros dispositivos de creación de los tres organismos reguladores iniciales de la liberalización surgieron fuera del paquete normativo de 1991. Así en diciembre de 1992, en medio del régimen del auto-golpe, se creó el regulador con las dosis de protección organizativa más tenues y con un ordenamiento sumamente disperso, la denominada suNASS encargada de proponer "las normas para la prestación de los servicios de agua potable, alcantarillado sanitario y pluvial, disposición sanitaria de excretas, reúso de aguas servidas y limpieza pública, fiscalice la prestación de los mismos, evalúe el desempeño de las entidades que los prestan, promueva el desarrollo de esas entidades, así como aplique las sanciones que establezca la legislación sanitaria y recaude las multas y tasas que esa misma legislación disponga" (ver el artículo 1 del Decreto Ley n. ${ }^{\circ} 1$ 25965). Posteriormente, el artículo 1 de la Ley n. ${ }^{\circ} 26.734$ de 1996 creó el OSINERG (ahora llamado OSINERGMIN) como "organismo regulador, supervisor y fiscalizador de las actividades que desarrollan las personas jurídicas de derecho público interno o privado y las personas naturales, en los subsectores de electricidad, hidrocarburos y minería". Finalmente, unos años después en 1998, el legislador mediante los artículos 2 y 3 de la Ley n. ${ }^{\circ} 26917$ ordenó la creación del OSITRAN para intervenir en la infraestructura nacional de transporte de uso público y "regular el comportamiento de los mercados en los que actúan las Entidades Prestadoras, así como, el cumplimiento de los contratos de concesión, cautelando en forma imparcial y objetiva los intereses del Estado, de los inversionistas y de los usuarios".

30 La SUNASS es el ejemplo más claro de la inclusión de una organización cuasi-regulatoria en un proceso de reforma estatal, sin que necesariamente existan espacios de privatización reales (la privatización de empresas estatales no es un presupuesto para su surgimiento). Esto es fácilmente demostrable pues en 1998 la naciente SUNASS había reconocido en su sector a 145 empresas prestadoras de saneamiento (EPS) incluyendo a la poderosa empresa estatal SEDAPAL. El resto de estos operadores eran de propiedad de una serie de municipalidades.

31 Jorge Danos Ordoñez, "Los organismos reguladores de los servicios públicos en el Perú", Revista Peruana de Derecho de la Empresa, n. ${ }^{\circ} 45$, Lima: Asesorandina, 2000, p. 61. 
del transporte terrestre, aéreo, marítimo, ferrocarrilero y fluvial, marcaron el inicio del modelo de competencia y de un incipiente régimen de fallos de mercado (por una asignación ineficiente de recursos mediante precios) que intento adaptar las ideas económicas de la public choice y de ciertos datos de la regulation norteamericana ${ }^{32}$, bajo las cuales el "Estado debe regular para corregir este fallo [...] el mercado puede recuperar su lógica natural y alcanzar, por consiguiente, el óptimo paretiano" ${ }^{133}$.

Es decir, en este inicial nuevo marco regulatorio el Estado debe eliminar todas aquellas restricciones y barreras burocráticas que tienden a aumentar los costes de transacción, para lograr que los monopolios naturales puedan operar eficientemente sin que se deteriore la calidad del servicio o se generen precios que impliquen un abuso de posición de dominio de ciertos operadores. Esto luego decantará en la necesidad de ejercitar un supuesto nuevo cúmulo de poderes de la "regulación" mediante formas organizativas independientes, transparentes y eficientes, pero siempre ligadas a ámbitos de fuerte contenido económico (con posibilidades de rentabilización empresarial), los cuales marcarán una tendencia de origen -no justificada- de reducción de sus papeles en la realidad actual ${ }^{34}$.

32 Se nota mucho la influencia de la escuela económica de Chicago en una serie de documentos sobre la regulación y el papel de los organismos reguladores peruanos. Por todos se pueden revisarse las ideas vertidas en el siguiente enlace: https://www.osiptel.gob.pe/ Archivos/Publicaciones/MMartinez_Chiclayo.pdf [Última revisión: 22/03/2017].

33 Andrés Betancor RodríGuez, Regulación, mito y derecho: Desmontando el mito para controlar la intervención de los reguladores económicos, Madrid: Civitas, 2010, p. 103. Debe aclararse que en el pasado las fallas del mercado constituyeron un argumento que ha servido para que el Estado proveyera directamente todos los bienes y servicios posibles, creándose la idea extendida en el país del Estado productor.

34 Creo firmemente, tal como pude adelantar en anteriores partes de este trabajo, que sí existen en nuestra realidad actividades diversas que mezclan a operadores privados y públicos en aspectos tradicionalmente "sociales" (asistencia sanitaria, educación, etc.), pero que sin embargo muestran fuertes aspectos de incidencia empresarial, mercados y nociones económicas podrán existir los presupuestos y contenidos suficientes para pensar en la aparición de potestades "regulatorias" para evitar daños a terceros, asegurar que estas actuaciones prestacionales "sociales" internalicen los costes que generan y, por último, puedan tutelar la utilización racional de todo tipo de bienes públicos. Ver estas ideas en José Laguna de PaZ, Derecho administrativo económico, Navarra: Thomson-Reuters, 2016, p. 35. Por eso, estimo es posible la creación y funcionamiento de organismos reguladores para servicios esenciales de diversa índole (de doble iniciativa sobre todo), siempre que el legislador los permita, generando -en paralelo- la reducción o limitación de la jerarquía y las potestades de las administraciones públicas del Estado (y el propio gobierno). En cualquier caso, en la actualidad muchas de estas consideraciones aparecen reflejadas en los "organismos reguladores en la sombra", organizaciones instrumentales que sin tener la denominación y algunos rasgos, se acerca y casi son estas entidades administrativas distintas. Del estatuto de algunas de estas entidades administrativas me ocuparé en la última parte de este capítulo. 
Lo anterior es el punto de partida de los "entes" reguladores peruanos, alejándose así del influjo gubernamental y la política, mostrando razonada autonomía, brindando a los inversores en ciertos sectores liberalizados o de nuevas infraestructuras en red, dosis de transparencia, velando al mismo tiempo por un trato imparcial frente a estos que permita dirimir controversias e incertidumbres. Finalmente, garantizando el acceso y los derechos de los usuarios del servicio o el emprendimiento correspondiente. En suma, la finalidad última

de la creación de los organismos anteriormente mencionados, fue la de garantizar un tratamiento técnico de la regulación y supervisión de las actividades económicas calificadas como servicios públicos, o que se desarrollan en condiciones de monopolio natural o poco competitivas y las que requieren para su desarrollo la utilización de redes e infraestructuras ${ }^{35}$.

\section{UNA CATEGORÍA PARA LOS ORGANISMOS REGULADORES}

Más allá de la heterogénea denominación utilizada casuísticamente y que puede llevar a confusiones (entre superintendencia y organismos), el ordenamiento peruano reconoce que los organismos reguladores pueden quedar calzados como administraciones públicas instrumentales, los cuales evidentemente nacen por un mandato fundacional del legislador, con personería jurídica-pública propia y otorgada directamente por norma legal, con un nivel dependencia a una de las tres administraciones públicas territoriales (la estatal), pero sin las dotaciones de independencia intensa y que particularmente la CP (y también la antigua Constitución) sólo otorga y reserva para las verdaderas administraciones públicas independientes (especie de organización administrativa institucional, que como adelanté sólo puede ser predicada para el Jurado Nacional de Elecciones, la SBS y el BCR).

Al respecto, el profesor Abruña ha sido bastante claro en clasificar a este tipo de entidades administrativas, siendo jurídicamente posible que la siguiente definición que citaré pueda ser trasladable a su aparición e incluso resulte aplicable en las actuales circunstancias (dada la falta de cambio legislativo o constitucional sobre la independencia). Los organismos reguladores fueron y son organizaciones instrumentales, en tanto, aparecen configurados por el legislador con una

cierta autonomía relativa con respecto a una organización pública superior, corporativa o estrictamente institucional, de la que dependen y a la que sirven. Son manifestaciones del uso de la técnica de descentralización, pero encierran en sí un 
fenómeno complejo en el que con una base común, personalidad jurídica y cierta autonomía, los fines, medios, dependencias y sujeción al Derecho Público pueden ser muy diversos. Son creadas para gestionar una actividad propia de la Administración Pública de la que dependen, de ahí que se les denomine instrumentales ${ }^{36}$.

Es más, en concordancia con esta anterior categoría que desmitifica la supuesta independencia de los organismos reguladores respecto del Gobierno y el conjunto del Poder Ejecutivo, estas entidades administrativas de la liberalización surgieron como fenómenos organizativos de una desconocida descentralización por servicios ofuncional, concepto que sin embargo aparecía reconocido expresamente en el antiguo Decreto Legislativo n. ${ }^{\circ} 560$. En esta norma se permitía la creación de entidades administrativas dependientes del presidente del Consejo de Ministros, dedicadas a diversas actuaciones, pero con algún nivel de autonomía administrativa (ver los artículos 55, 56 y 57 del citado dispositivo). En años posteriores del presente siglo, esta misma noción de descentralización funcional quedó reconocida en la actual LOPE a través de las denominadas entidades del Poder Ejecutivo que quedaron adscritas a un específico ministerio. Estas últimas pueden ser de dos tipos: i) los organismos públicos ejecutores, y ii) los organismos públicos especializados (ver los artículos 28 y 29 de la Ley n. ${ }^{\circ}$ 29.158). Justamente dentro de esta última subcategoría se ha reconocido a los organismos reguladores como entidades de intervención básicamente economicista, puesto que actúan "en ámbitos especializados de regulación de mercados o para garantizar el adecuado funcionamiento de mercados no regulados, asegurando cobertura de atención en todo el territorio nacional" (ver el artículo 32 de la Ley n. ${ }^{\circ} 29.158$ ).

En suma, aunque la actual normatividad de organización de la administración del Estado presenta un nivel más alto de autonomía a favor del desenvolvimiento de los organismos reguladores, en virtud de la abierta eliminación de una serie de antiguas y expresas declaraciones de dependencia o pertenencia que se pueden revisar en las normas legales de creación de estas entidades ${ }^{37}$, lo cierto es que antes y ahora puede catalogárseles como administraciones institucio-

36 Antonio Abruña Puyol, Delimitación jurídica de la administración pública en el ordenamiento peruano, Lima: Palestra, 2010, pp. 180-181.

37 Por ejemplo, resultaba bastante claro el original artículo 80 del Decreto Legislativo n. ${ }^{\circ}$ 702 que señalaba al OSIPTEL como "un organismo público dependiente directamente del Presidente de la República, con autonomía administrativa, económica, financiera". En el mismo sentido aparece el artículo 1 de la Ley n. ${ }^{\circ} 26.734$ que aunque declara al inicial osINERG como entidad con "personería jurídica de Derecho Público Interno" y con un nivel alto "de autonomía funcional, técnica, administrativa, económica y financiera", aparecía configurado finalmente con un nivel de "pertenencia" al Ministerio de Energía y Minas. Más gráfica resultó la expresión contenida en el artículo 1 del Decreto Ley n. ${ }^{\circ} 25.965$ por la que se declaró que la sunass es "una Institución Pública Descentralizada" y autónoma, pero "perteneciente" al desaparecido Ministerio de la Presidencia. 
nales instrumentales capaces de tener un ámbito de protección con niveles intensos de autonomía que deben ser sostenidos desde formas diversas (principalmente en la selección de sus directivos y otros mecanismos que permitan aislar su desempeño competencial). Sin embargo, dada su manifestada categorización, siempre serán entidades administrativas necesitadas de que el legislador apruebe y extienda ciertos modos de lejanía y no intervención sujetoria por parte del Gobierno y las propias administraciones ministeriales.

Así, los organismos reguladores son depositarios y claras muestras organizativas de la descentralización funcional que imperó y hasta ahora subsiste en nuestro derecho administrativo de la organización, apareciendo la última como una noción centrada en dotar al sujeto creado de una personalidad jurídica-pública distinta y propia, además de una serie de medios materiales, humanos y competenciales, pero siempre con algún de dependencia respecto de la organización administrativa fundadora, dato de origen que permite el nacimiento de múltiples opciones organizativas con más o menos niveles de autonomía administrativa, funcional, económica-financiera, de personal ${ }^{38}$. En particular, y como una muestra concreta de la amplitud de supuestos que recoge la descentralización funcional peruana, los organismos reguladores se ubicaron y mantienen una posición de tutela y protección distinta incluso respecto de otras integradas en el conjunto de entidades instrumentales del Poder Ejecutivo ${ }^{39}$, dado su papel y la necesidad de muestras o manifestaciones

Ver sobre los conceptos de la administración institucionales y la descentralización funcional en Jesús Caballero Ortiz, op. cit.; Gaspar Ariño Ortiz, "Modelos comparados: El contexto iberoamericano", Regulación económica. Lecturas escogidas, Madrid: Thomson-Reuters-Aranzadi, 2012.

39 Una muestra incompleta y por pulirse de esta protección diferenciada es el régimen de los órganos de gobierno de estos prganismos reguladores. El legislador indica que estas entidades suministrativas se encuentran dirigidas "por un Consejo Directivo. Sus miembros son designados mediante concurso público. La ley establece los requisitos y el procedimiento para su designación. Sólo podrán ser removidos en caso de falta grave e incompetencia manifiesta debidamente comprobada, y con el voto aprobatorio del Consejo de Ministros. La Ley establece el procedimiento para su cese" (ver numeral 6 del artículo 32 de la Ley n. ${ }^{\circ}$ 29.158). Al respecto creo que la única de construir un régimen de directivos de los organismos reguladores alejado de los políticos es configurarlo como un componente o escalera final de una especial carrera profesional y pública del personal regulatorio, en la que existan posibilidades de concursos internos de ascenso entre los funcionarios que desde siempre han trabajado en el ejercicio de potestades y actuaciones de sectores regulados. No creo que el actual esquema de concursos públicos y designación con remoción por causales tasadas dirigidos por la Presidencia del Consejo de Ministros sea del todo malo respecto de la protección de la autonomía de la organización regulatoria, sin embargo nunca podrá ser comparable con un sistema de carrera que permita elegir a los mejores dentro del grupo de funcionarios concursados (que no le deben el puesto a nadie más que a sus capacidades y méritos personales). Vale decir que el legislador peruano podría construir, a razón de la ley del servicio civil y la irrupción de un modelo de carrera vertical y horizontal, un 
concretas de despolitización que exigía el inicio de la liberalización ${ }^{40}$, aunque siempre aparecerán rasgos de su vinculación de dependencia o cierto nivel de subordinación con el gobierno y ministerios ${ }^{41}$.

Incluso esta mencionadas extensión y diversidad subsisten hasta el día de hoy. Al respecto, dadas las similitudes entre las subcategorías de organismos públicos del Poder Ejecutivo y el dato de la independencia competencial "con arreglo a su Ley de creación" que otorga el legislador al barrido para los organismos reguladores y otra modalidad de entidad instrumental (ver el artículo 31 de la LOPE), es que en el seno de nuestra descentralización funcional se viene produciendo un fenómeno extraño de intercambiabilidad y relativización de las denominaciones aplicadas al conjunto de estas puntuales organizaciones administrativas, bajo el cual se puede indicar normativamente una nomenclatura y supuestas diferencias funcionales u organizativas, pero en la realidad terminan apareciendo más cercanías que diferencias entre las administraciones públicas comparadas. Por tanto, a pesar de que el legislador pretenda plantear distancias entre los denominados organismos reguladores y los organismos técnicos especializados, algunas de las entidades administrativas creadas dentro de la última subcategoría aparecen ejercitando labores propias y conformadas con la estructura propia de un organismo regulador, aunque con protecciones y garantías más tenues (a pesar de la independencia funcional general preceptuada por la propia LOPE ${ }^{42}$.

Por último el TCP, aunque no ha construido nociones organizativas aplicables a los organismos reguladores, lo cierto es que en algunas sentencias de la década pasada ha intentado reforzar el valor de la autonomía de estas

sistema especial y distinto para este personal administrativo tan particular, incluyendo en la capa superior a sus respectivos directivos y gerentes.

40 La preocupación por la obligatoriedad de la despolitización de los reguladores se ha mostrado en diferentes países occidentales. Así, un importante autor hace algunos años atrás consideraba que parte de las comisiones reguladoras de los servicios de red españoles habían sido copados: "Los partidos políticos las han invadido, sus decisiones y las votaciones en su seno han estado cada vez más 'alineadas', según las posiciones políticas de quienes nombran a sus miembros, con o sin instrucciones; las injerencias políticas en ellas han sido crecientes, y ello alcanzó su clímax cuando hace ya más de dos años (abril de 2007) el presidente de la CNMV decidió dimitir ante el intervencionismo gubernamental en la OPA sobre Endesa de Enel y Acciona". Ver este comentario crítico del profesor G. ARIÑO, en el siguiente enlace: http://www.expansion.com/2009/07/17/opinion/1247861372.html [Última revisión: 23/03/2017].

41 Una muestra actual de esta dependencia o subordinación específica y controlada de los organismos reguladores peruanos es que estas entidades deberán determinar "su política de gasto de acuerdo con la política general de Gobierno" (ver el numeral 1 del artículo 32 de la señalada LOPE).

42 En suma, dada su falta de sistemática y coherencia, el legislador peruano superó hace buen tiempo el listado "cerrado" de organismos reguladores establecido en el artículo 1 de la Ley.$^{\circ} 27.332$. 
entidades administrativas, comprendiendo que esta característica otorgada por el legislador es muy valiosa para recubrir el correcto ejercicio de las potestades regulatorias y su propio funcionamiento de cara al interés público. Así, el Alto Tribunal ha indicado que la "supervisión del cumplimiento de los fines de la concesión está a cargo de órganos autónomos creados por Ley, como OSIPTEL o INDECOPI. Estos órganos están obligados a tutelar el derecho de los usuarios, así como el interés público, y para ello deben controlar que la prestación del servicio se realice en óptimas condiciones y a un costo razonable"43. Además, el TCP intuye la necesidad de componentes organizacionales distintos de estas entidades señalando que el "Estado a través de los denominados Organismos Reguladores, controla la calidad y condiciones del servicio, fija la tarifa y garantiza, a su vez, generar condiciones de competencia en los segmentos donde esta sea posible" ${ }^{\prime \prime 4}$.

\section{LOS ORGANISMOS REGULADORES NACIERON Y CONTINÚAN COMO CUASI-INDEPENDIENTES}

Considero que un dato distinto y novedoso de los organismos reguladores creados al inicio de la liberalización peruana es el relativo nivel de cuasiindependencia con la que aparecieron, debiendo entenderse que este dato organizativo es consecuencia de las distintas formas de autonomía reconocidas legislativamente (casi siempre relacionadas con aspectos administrativos, económico-financieros y de gestión) y que no quitan ni aportan nada respecto de su categorización como entidad instrumental, aunque sí abren el espacio para construir su régimen especial de organización. En suma, se tratan de administraciones públicas surgidas con un amplio manejo técnico, funcional y capacidad para auto-organizarse y auto-administrarse (siempre con ciertos límites), pero sin la posibilidad de ser independientes, en tanto, separadas política y completamente del Gobierno y la administración del Estado. Si se quiere surgieron para tener un

ámbito de libre determinación, y la consiguiente relegación de la Administración gubernativa a un control esencialmente defensivo, es decir, más centrado en evitar que la entidad lesione intereses generales en el proceso de satisfacción de los intereses colectivos sobre los que se estructura, que en guiarla en el servicio de estos últimos ${ }^{45}$. 
Sobre esto último, aunque la autonomía (y su producto específico: la cuasi-independencia) y la independencia puedan plantear la posibilidad de una diferencia de grado o intensidad, que no sólo se manifiesta en las distintas categorizaciones de entidad administrativa instrumental y administraciones independientes, considero que en el caso de los iniciales organismos reguladores es mejor diferenciar a estas nociones en clave cualitativa puesto que la independencia siempre supone el rompimiento "de la relación de instrumentalidad. Ruptura que no va dirigida a hacer posible la autoadministración, sino la neutralización política de una determinada actividad administrativa" ${ }^{\prime \prime 6}$.

A partir de la distancia conceptual planteada, es evidente que la completa neutralización política del Gobierno nunca fue ni será predicable para nuestros organismos reguladores (entendido este concepto en un sentido jurídico de nula posibilidad de dirección del políticamente elegido o designado por este dentro del Poder Ejecutivo ${ }^{47}$ ), aunque tengan reconocidos por el legislador un gran espacio y márgenes de maniobra para servir de manera mucho más neutral y objetiva a los intereses públicos sectoriales aparecidos en ámbitos prestacionales o de infraestructura en red. En suma, el término cuasi-independencia, dada la posibilidad terminológica que existe en nuestro derecho, abre el espacio para mostrarse como una denominación sintética que resume y junta a las diferentes autonomías reconocidas expresamente por el legislador respecto de estas específicas entidades instrumentales (tanto antes como en la actualidad).

En adición, aunque se trate de una cuestión adaptada a la tercera etapa y a las vigentes reglas implantadas por la LOPE, bien vale la pena entender que la cuasi-independencia es la interpretación correcta de la genérica y actual calificación legal dada a los organismos reguladores como entidades administrativas con "independencia para ejercer sus funciones con arreglo a su Ley de creación" (ver el artículo 31 de la LOPE). El contenido de esta protección funcional esta emparentado a lo que Sánchez Morón denominó autonomía de gestión, noción que siempre resulta "limitada en todo caso [ ... ] aquellos organismos dependen de una Administración territorial (a través de un ministerio en el caso del Estado)"48.

Pero regresemos a los inicios. Ahora bien, esta característica esencial mostrada en la primera legislación de creación de los organismos reguladores se basa en dos pilares fácilmente discernibles y de permanente aparición positiva (incluso en las etapas posteriores al término de ola liberalizadora), a saber, los aspectos propios respecto de "las autoridades que integran su máximo órgano colegiado, además de su presidente, que no pueden ser cesados libremente por

47 Antonio Abruña Puyol, Delimitación jurídica de la administración pública en el ordenamiento peruano, Lima: Palestra, 2010, p. 185. 
el Gobierno"49. En segundo la existencia de "una prohibición de impartición de órdenes e instrucciones por parte de este que lo aleje de la función asignada"50.

En ese sentido, estos fundamentos diagraman los tipos de cuasi-independencia de los reguladores (o notas cercana a ella), las cuales deben aparecer efectivamente para ser considerados como tales (más allá del mero reconocimiento normativo). Existiendo así la orgánica y la funcional, ambas siempre respecto del Gobierno de turno. La primera está referida al nombramiento, remoción y cese de sus directivos y los mecanismos que se usan para tales fines (el estatuto personal de estos máximos funcionarios públicos). La segunda se encuentra planteada con respecto a la existencia de una relación de jerarquía, tutela o control del mismo Gobierno respecto de estas entidades manifestada en el dictado de instrucciones o directrices de obligado o vinculante cumplimiento, o mediante la posibilidad de modificar acto resolutivos o decisiones regulatorias mediante algún tipo de recurso administrativo o mecanismo propio del ejercicio de potestades gubernativas (el encuadre organizativo y funcional del Gobierno ante estas nuevas entidades administrativas).

Vale decir que a partir de la influencia anglosajona con la que se fundaron nuestras organizaciones regulatorias, la cuasi-independencia fue intentada de ser asumida como un "supuesto aislamiento" de la influencia del poder encarnado en el Poder Ejecutivo, buscando separar la política y la administración, a partir de una intensa autonomía organizativa y la imposibilidad de intervención, participación conjunta o revisión de roles por parte de los Gobiernos y otras administraciones públicas. Sin embargo, esta última posición extrema y ya entrada en años no encuentra encaje constitucional actual y supone el desconocimiento de una serie de razones técnicas, de gestión y jurídicas que han ido por un camino más cercano a la conjunción de esfuerzos administrativos, a fin de afrontar mercados ordenados no sólo por las primeras entidades administrativas (tal como actualmente viene sucediendo con el Organismo de Fiscalización Ambiental y su espacio competencial compartido con los organismos reguladores clásicos creados al inicio de la ola liberalizadora) ${ }^{51}$.

A partir de esta cuasi-independencia de doble modalidad se puede construir una serie de adicionales consideraciones definitorias de estas entidades instrumentales. La más importante es la especialidad de esta organización administrativa con la que apareció para afrontar la transformación de los sectores despublificados, con el propósito de asumir el papel de garante, supervisor y vigilante de las prestaciones brindadas por terceros, además del competente para el ejercicio de potestades de "asignación de medios escasos o a la 
imposición de obligaciones adicionales de servicio" ${ }^{152}$. En ese sentido, como bien ha afirmado el profesor Betancor, deben convertirse en organizaciones administrativas con algún nivel de independencia cuya especialización afecta a

la función y a la organización. Esta es una organización especial para desarrollar una función especial. La especialidad de la organización tiene por finalidad facilitar la especialización adecuada para el óptimo desarrollo de la intervención regulatoria en el contexto de las singulares circunstancias del mercado. La regulación precisa reguladores y estos deben ser tan especiales como la regulación que han de desenvolver que, a su vez, será tan especial como el mercado sobre el que se va a proyectar dicha intervención ${ }^{53}$.

Por otro lado, aparejadas a las dos anteriores aparece la imparcialidad, que también resultó muy resaltada en el régimen de creación de estas organizaciones administrativas ${ }^{54}$, característica que aparece pensada para reforzar la neutralidad y objetividad técnica con la que deben desenvolverse en los sectores liberalizados, principalmente en el desempeño de las llamadas potestades administrativas parajudiciales (de resolución de conflictos e incertidumbres mediante impugnaciones), las cuales, como bien afirmó Abruña (para todas las administraciones públicas incluyendo las regulatorias) no representan

expresión de potestad judicial [...] pues sus actos son realizados en virtud de una potestad administrativa que se encuentra revestida de la presunción iuris tantum de legalidad, a diferencia de la presunción iuris et de iure de legalidad de la que están dotados los actos realizados en virtud de potestad judicial ${ }^{55}$.

Para cerrar las relaciones conceptuales de la cuasi-independencia vale indicar que aunque no aparecen expresamente reconocidas en los dispositivos iniciales, existen dos características adicionales que se enlazan con esta noción y aparecen implícitas en estos textos legislativos. Estas nociones han sido muy bien planteadas por Betancor y han servido para otorgar la cobertura suficiente: i) al nacimiento de mecanismos para solucionar los conflictos de interés aparecidos en supuestos concretos (monopolios naturales y los servicios en red) $i \mathrm{y}_{\text {, }}$ ii) para crear instrumentos $y$ actuaciones que permitan tener cierta credibilidad

52 Eberhard SChmidt-Assmann, La teoría general del derecho administrativo como sistema, Madrid: Marcial Pons, 2003, p. 257.

53 ANDRÉS BETANCOR, op. cit., pp. 317-318.

54 Ver esta característica implícitamente recogida en el original artículo 79 del Decreto Legislativo N ${ }^{\circ} 702$ tras el ámbito objetivo del OSIPTEL como entidad administrativa encargada en el servicio de telecomunicaciones de "garantizar la calidad y eficiencia [...] brindado al usuario y de regular el equilibrio de las tarifas".

55 Antonio Abruña Puyol, Delimitación jurídica de la administración pública en el ordenamiento peruano, Lima: Palestra, 2010, p. 113. 
ante los sujetos del mercado liberalizado ${ }^{56}$. Ambas no han tenido desarrollo en las actuales circunstancias, aunque aparecen pensadas en ciertas políticas de comunicación institucional y datos del empleo público practicados por estas organizaciones regulatorias.

Como última cuestión es necesario indicar que la cuasi-independencia aparecida durante el surgimiento de las organizaciones regulatorias, al estar basada en la autonomía y otros datos organizativos planteados por el legislador en cada norma de creación (esencialmente los niveles de dependencia o vinculación sujetoria), no siempre pudo (y podrá) atribuirse de igual manera a los organismos reguladores iniciales (ni tampoco a los nuevos que se han creado a partir de la segunda etapa antes mencionada). Esta cuestión de disparidad en el tratamiento determina la necesidad de revisar casuísticamente sus regímenes de autonomía, bajo la idea de una manifiesta diversificación organizativa regulatoria ${ }^{57}$.

Así, puede establecerse un primer grupo de reguladores en los que la cuasiindependencia se configuró con múltiples ámbitos de auto-organización y auto-administración, básicamente en aspectos administrativos, económicos, financieros y en los que aparecieron finalmente reflejados en una lenta construcción de la selección y remoción diferenciada de directivos y menos niveles de sujeción respecto del propio presidente de la República o de una concreta entidad ministerial (cuestiones que sobre todo se afianzaron durante la segunda etapa, a partir de la promulgación de la Ley n. ${ }^{\circ}$ 27.332). En este grupo puede considerarse a OSIPTEL, OSINERG y OSITRAN, todas entidades regulatorias en las que se puede revisar unos iniciales datos de fuerte y estricta dependencia ${ }^{58}$, pero con dosis altas de autonomía funcional, que terminaron por ensamblar una ordenación propia y equilibrada con potestades protegidas.

El segundo grupo está conformado en solitario por la SUNASS, entidad instrumental que, como adelanté al inicio de este capítulo, no surgió como una directa consecuencia o necesidad de respuesta regulatoria en el sub-sector saneamiento (sino como producto del proceso de reforma y disminución del aparato de la administración estatal), apareciendo en sus orígenes con una dependencia directa a una extinta organización ministerial (el Ministerio de la Presidencia), "con personería de derecho público" y "patrimonio propio y autonomía funcional, económica, técnica, financiera y administrativa" (ver el artículo 1 del Decreto Ley n. ${ }^{\circ}$ 25.965). El dato diferenciador en este regulador se encontraba en el señalamiento como único órgano de gobierno al 
correspondiente superintendente, sin que ningún consejo directivo aparezca en esta posición máxima, situación que en la práctica aminoró las posibilidades reales de autonomía funcional de esta organización regulatoria, puesto que la designación de este órgano unipersonal correspondía "al Presidente de la República, a propuesta del Ministro de la Presidencia, mediante Resolución Suprema" (ver el artículo 16 de la Ley n. $\left.{ }^{\circ} 26.284\right)^{59}$.

Debe indicarse que la evolución legislativa y reglamentaria colaboró mucho en fortalecer una cuasi-independencia más vertebrada y real de ambos grupos durante la segunda etapa de la historia de los organismos reguladores, demostrada -en concreto- con la introducción de un esencial y estándar régimen de acceso y remoción regulada del conjunto de directivos de estas entidades. En ese sentido, nunca debe dejar de tomarse en cuenta a la Ley n. ${ }^{\circ} 27.332 \mathrm{co}-$ mo la reductora del margen de las remociones ${ }^{60} \mathrm{y}$, en fechas posteriores, a la esencial reforma de origen reglamentario que permitió la primera aplicación de concursos públicos ${ }^{61}$ como técnica de salvaguarda de las designaciones del presidente y miembros en los respectivos consejos directivos, permitiéndose así algún grado de aplicación de los principios de igualdad, mérito y capacidad.

En suma, en la etapa de la unificación normativa se produjo un reforzamiento muy importante de la cuasi-independencia orgánica, aunque algunos datos de esta época reflejan también la disminución de la intensidad de la dependencia al eliminarse este término de la definición contenida en el artículo 1 de la Ley n. ${ }^{\circ}$ 27.332. Quedando los organismos reguladores reforzados en su ámbito competencial y autonomía funcional (al eliminarse cualquier forma de práctica de potestades de dirección activa y directa), pero nunca desligados de una

También puede revisarse esta diferencia organizativa de la naciente SUNASS en JORGE DANOS, op. cit., p. 67.

60 El reformado numeral 6.4 de esta ley reducía las causales de remoción de miembros sólo a los casos "de falta grave debidamente comprobada y fundamentada, previa investigación en la que se les otorga un plazo de quince (15) días para presentar sus descargos, de conformidad con lo que se señale en sus respectivos reglamentos".

61 A pesar que la Ley n. ${ }^{\circ} 27.332$ sólo presentaba un régimen de acceso mediante designaciones, la posterior norma reglamentaria contenida en el Decreto Supremo N. ${ }^{\circ}$ 014-2008PCM en sus artículos 2 y 9 admitió por primera vez el ingreso de directivos de organismos reguladores mediante concursos públicos, abiertos y mediante la actuación de una comisión evaluadora integrada por cuatro integrantes de corte técnico (que representaban a los ministerios impactados por la actividad regulada). En este esquema de selección que se mantiene hasta la actualidad, una vez terminado el concurso, la comisión selecciona una terna de candidatos que era dada a conocer al presidente del Consejo de Ministros y este, a su vez, lo presentaba al presidente de la República. Finalmente es el presidente de la República quien designa -de manera discrecional asumiendo cualquiera de las tres opciones-mediante resolución suprema a los miembros o miembro que integrarán el Consejo Directivo del regulador. En conclusión esta norma reglamentaria creó un sistema de acceso mixto o intermedio para la alta burocracia de los organismos reguladores (en el que se mezclan las fórmulas de concurso público y el sistema de libre designación política). 
vinculación y control de protección por parte del Gobierno (esencialmente para evitar cualquier lesión de intereses públicos y otras cuestiones puntuales de política general que no podían dejan de ser asumidas por el Gobierno) ${ }^{62}$.

Todos estos avances terminaron configurando las entidades administrativas que ahora conocemos y que se sostienen sobre la base de un régimen de apariencia estatutaria ${ }^{63}$ compuesto por una garantía legal y reglamentaria de "especial autonomía técnica y funcional respecto del poder político" ${ }^{64}$. La superación de la dependencia y control positivo que previó el legislador en los primeros años de la liberalización y que se extendió hasta terminar la primera década del siglo pasado terminó transformándose completamente, permitiendo luego un segundo periodo de configuración como entidades administrativas con un importante cuasi-independencia protegida, pero que siguen manteniendo la incardinación y el valor de su instrumentalidad dentro del conjunto administraciones públicas estatales ubicadas en el Poder Ejecutivo.

\section{EL PRIMER ORDEN COMPETENCIAL DE LOS REGULADORES}

El surgimiento de este tipo de entidades administrativas estuvo marcado por un orden competencial disímil ${ }^{65}$, en razón de la dispersa normatividad que

62 Mariano Magide Herrero, Limites constitucionales de las administraciones independientes, Madrid: INAP, 2000, p. 57.

63 Indico la condición de "apariencia estatuaria" pues aparece como un régimen de reglas cerradas e imposibles de ser ampliadas en cuanto a los destinatarios (ver la lista de $n u$ merus clausus del artículo 1 de la Ley $n{ }^{\circ}$ 27.332), debido a la singularidades funcionales y organizativas de los organismos reguladores, pero que sin embargo, dado el desorden de nuestra descentralización funcional y la falta de un adecuado derecho de la organización, ha llevado al acercamiento muy estrecho de algunas entidades instrumentales de reciente creación para situarse en la posición de auténticos reguladores en la sombra, a pesar de denominarse y asimilares a la subcategoría legislativa de "organismos técnicos especializa-

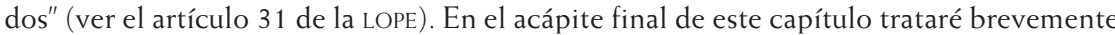
sobre esta cuestión tan actual, pero necesitada de contrastar respecto a los inicios de la liberalización.

64 JorGe DanOS, op. cit., p. 63.

65 Existieron un total de cinco leyes que habilitaron de diferentes potestades a los nacientes organismos reguladores, a saber: el Decreto Legislativo n. ${ }^{\circ} 702$ (artículos 80, 81 y 82) para el OSIPTEL, la Ley n. ${ }^{\circ} 26.284$ (artículos 10 al 15) y el Decreto Ley n. ${ }^{\circ} 25.965$ (artículo 1) para la SUNASS, la Ley n. 26.734 (artículo 5) para el OSINERG y, por último, la Ley $n .{ }^{\circ}$ 26917 (artículos 4 al 8) para el OSITRAN. Posteriormente, el legislador ha tenido un intento fallido por intentar uniformizar el orden competencial mediante la implantación de un solo régimen de potestades (ver los artículos 3, 4 y 5 de la Ley n. ${ }^{\circ} 27.332$ ), sin embargo al dejar vigentes todas las normas de creación (con una derogación diferida y supeditada a la producción de los nuevo regímenes, los cuales en muchos casos nunca se crearon, salvo alguna excepción), permitió la coexistencia de un orden competencial único y las potestades específicas y propias habilitadas durante la primera fase de creación. Es decir, 
acompañó y otorgó cobertura a sus sucesivas creaciones, característica última manifestada con la promulgación de alguna norma legal extra que se necesitó para terminar de completar el proceso de habilitación de potestades administrativas a favor de estas nuevas organizaciones instrumentales. A pesar de este inicio algo caótico, lo cierto es que sí es posible encontrar un núcleo de potestades básicamente centradas y de cobertura en el régimen de policía administrativa (el grupo de funciones más importante y representativo), potestades regulatorias no limitatorias, sumadas a potestades reglamentarias, auto-organizativas y de corte interno y parajudiciales, las cuales -más allá y salvo denominaciones disímiles aparecidas con las atribuciones dispersas- se han mantenido hasta la actualidad (ver los vigentes artículos 3, 4 y 5 de la Ley . $^{\circ}$ 27.332).

El primer conjunto son potestades que resultan completamente explicables y contenidas en la clásicas técnicas de la policía administrativa ${ }^{66}$, salvo algunos agregados más recientes y bastante escasos de entidad conceptual ${ }^{67}$. Pudiendo clasificarse en: i) potestades de ordenación y control ${ }^{68}$ regulatorio destinadas a mantener y promover una competencia efectiva y justa entre los operadores (allí donde el sector lo permita) o de mantenimiento de estándares de calidad y eficiencia en las actuaciones prestacionales o correspondientes ejecuciones contractuales de las concesiones de la infraestructura del transporte y servicios (manifestada principalmente en la posibilidad de imponer órdenes, mandatos prohibitivos, y medidas correctivas); ii) potestades de supervisión y fiscalización ${ }^{69}$ referidas principalmente al contraste material, revisión del cumplimiento de diversas obligaciones normativas, contractuales y técnicas por parte de los correspondientes operadores y agentes regulados, todas las

mezcló el orden con la dispersión funcional, situación que demuestra la falta de sistémica y política normativa que nos acompaña en múltiples ámbitos de actuación.

66 Creo que el concepto de policía administrativa entendido como una categoría institucional en sentido estricto y manifestada en diversas potestades destinadas a limitar y delimitar derechos y libertades, a fin de mantener el orden público acotado.

67 Tal como lo ha podido demostrar el profesor Laguna de Paz. José Laguna de PAZ, Derecho administrativo económico, Navarra: Thomson-Reuters, 2016, pp. 33-34.

68 Jorge Danos, op. cit., p. 73. En la actualidad, es claro que estos mecanismos de control han tenido avances hacia técnicas más flexibles, aunque no con los nombres comunitarios, que por sobre todo buscan el cumplimiento de "deberes de información y transparencia, actividades comunicadas y declaraciones responsables [... procedimientos de evaluación y auditoría [...] que eliminan trabas burocráticas a las empresas". Ver esta cita en MigueL SÁnCHEZ Morón, op. cit., p. 644.

69 La fiscalización y supervisión por el estricto y necesario funcionamiento del sector para el cual han sido creados, y el diseño de mecanismos que permitan mayores niveles de bienestar para los usuarios de los servicios o infraestructuras bajo su competencia, han sido de las cuestiones que más ha resaltado el TCP para los organismos reguladores. Ver al respecto la STCP, recaída en el Exp. 0008-2003-AI/TC, 11 de noviembre de 2003, F.J 38, 39,40 y 41 . 
cuales quedarían enmarcadas en una gran competencia inspectiva ${ }^{70}$; iii) potestades de delimitación del contenido de los derechos de los regulados; iv) potestades de investigación preliminar y de indagación de medios indiciarios, que puede aparecer en paralelo o juntas con las anteriores; y v) potestades sancionadoras en contra de conductas tipificadas y cometidas por los sujetos regulados (lo cual incluía las sub-potestades de inicio, procesamiento, imposición de punición y ejecución de la misma).

En segundo lugar, las potestades regulatorias no limitatorias estaban principalmente compuestas por: i) competencias diversas de promoción, información y sostenimiento de la competencia leal en el sector regulado, además de "determinación de niveles de calidad y cobertura del servicio, y garantía de las condiciones de acceso a la actividad y utilización de las redes ${ }^{\prime \prime 7}$; ii) potestades tarifarias que permitieron establecer la remuneración de ciertos concesionarios de naturaleza privada ${ }^{72}$; iii) potestades de fijación de precios manifestada principalmente en las actuaciones del OSITRAN respecto a mercados relativamente competitivos en los que no existían clausulas tarifarias y con relación a "otros $\operatorname{cobros}^{\prime \prime 73}$; y iv) potestades de colaboración y asistencia con las entidades ministeriales competentes y cercanas al sector regulado.

Tanto las potestades de policía regulatoria como las no directamente limitantes habilitadas a favor de los cuatro organismos reguladores antes mencionados, conformaron la esencia de la primera cláusula del Estado regulador de origen legal, que restringió las labores prestacionales públicas, permitió la destrucción del estatismo y devolvió el protagonismo a los privados dentro de la vida social y económica del país (según lo reclamado por la subsidiariedad horizontal). Este

70 José Laguna de PaZ, op. cit., pp. 262-263.

71 Jorge DanOS, op. cit., p. 73.

$72 \mathrm{Al}$ respecto, debe entenderse que la tarifa "debería reservarse a la remuneración exigida por la prestación de un servicio a través de concesionario o de entidad que actúa en régimen de derecho privado. La tarifa no es un ingreso de derecho público y no es manifestación de la potestad tributaria. La tarifa es ejercicio de la potestad tarifaria que nace con la conversión de una actividad de contenido económico en servicio público. En este sentido su fijación es fruto de una resolución sometida al Derecho administrativo, pero esta resolución no debe adecuarse a la normativa tributaria. La determinación de la tarifa responde a la financiación del servicio y, en el caso del concesionario, se vincula a la formalización del contrato concesional. No es fruto de un acuerdo, pero queda anudada a la vida del contrato en virtud del principio del equilibrio financiero". Ver esta cita perfectamente adaptable a nuestro derecho de las concesiones de servicios en JOAQuín TORnOS Mas, "Potestad tarifaria y política de precios", Revista de Administración Pública, n. ${ }^{\circ} 135$, Madrid: Centro de Estudios Políticos y Constitucionales, 1994, p. 87.

73 Este tipo de precios distintos a las tarifas aparecen cuando existen "mercados que no funcionan en régimen de competencia efectiva [...]. Con frecuencia, este es el caso de los sectores verticalmente integrados, en los que la prestación de servicios requiere la utilización de infraestructuras difícilmente replicables". Ver esta cita en José LaGuna DE PAZ, op. cit., p. 258. 
orden competencial exacto adentró a estas nuevas entidades instrumentales en los caminos de la búsqueda del buen funcionamiento del mercado a través de la competencia y la libre concurrencia, pero sin dejar de preservar el equilibrio entre los intereses de los diferentes participantes (operadores, consumidores, usuarios, terceros interesados). Es desde esta doble perspectiva que los organismos reguladores peruanos encontraron su utilidad y justificación en cada uno de los sectores que sucesivamente fueron liberalizados.

Pero el recuento de las potestades definitorias e iniciales de los organismos reguladores no estaría completo si es que no se muestran algunas notas importantes sobre las potestades reglamentarias y parajudiciales, siendo ambas fundamentales para completar el mantenimiento de las condiciones adecuadas para superar y encontrar respuestas ante las disputas o incertidumbres de los participantes y, en adición, un marco de estabilidad jurídica apropiado que permite el despliegue de "la confianza en el respeto a las reglas de juego, favorece la seguridad jurídica, y con ello, el desarrollo de la actividad económica"74.

En primer término, las potestades reglamentarias fueron instrumentalizadas para ejecutar y desarrollar las incompletas y parcas normas legales de creación y funcionamiento de los organismos reguladores, esto a través del único tipo de reglamento que se conoce en nuestro derecho: el ejecutivo. Aunque muchas veces estas entidades administrativas buscaron plantear intentos o muestras efectivas de sobrepasarlo (mediante versiones de reglamentos independientes o, peor aún, a través de dispositivos infra-legales contra legem $)^{75}$.

Finalmente las potestades administrativas parajudiciales aparecieron en el causi-estatuto de los organismos reguladores -fundamentalmente- para ejecutar y viabilizar la función arbitral, la cual desde siempre los presentaba perfilados como entidades administrativas con algún grado de singularidad ${ }^{76}$. En ese sentido, como bien lo ha reconocido el profesor Abruña, estas últimas son potestades administrativas comunes dotadas de la típica condición jurídico-formal iuris tantum de legalidad (similar a cualquier otra practicada por las organizaciones

74 José Laguna de PaZ, op. cit., p. 267-268.

75 Quizás la muestra más clamorosa de reglamentos contra legem sean los primeras normas de los organismos reguladores que crearon los regímenes sancionadores regulatorios, los cuales aparecieron sin tipos infractores, sanciones y un procedimiento pre-establecidos en las leyes de creación y funcionamiento de estas entidades. Esto supuso una violación abierta de varios principios de derecho sancionador, pero adicionalmente una importante desconfiguración de la potestad reglamentaria regulatoria y del propio principio de reserva de ley. Por todas, ver el primer régimen sancionador de telecomunicaciones recogido en la Resolución del Consejo Directivo n. ${ }^{\circ} 001-96-\mathrm{CD} / \mathrm{OSIPTEL}$.

76 José Laguna De PaZ, op. cit, p. 33. En la doctrina peruana Tassano ha indicado que la función arbitral se aplica sobre el sector regulado con el propósito de buscar "el equilibrio entre los intereses de los usuarios, de los prestadores del servicio y del mismo Estado. Por ello, la regulación debe ser utilizada como un instrumento al servicio del mercado y no como un sustituto del mismo". Hebert Tassano Velaochaga, "Competencia y regulación", Revista de Derecho PUCP, n. ${ }^{\circ}$ 76, Lima: Pontificia Universidad Católica del Perú, 2016, p. 111. 
administrativas) y cuyos actos administrativos producidos en sus respectivos ejercicios siempre se encuentran sometidos al posterior control judicial. Sin embargo, estas competencias materialmente presentan aspectos de resolución de conflictos o disputas y eliminación de incertidumbres diversas entre privados intervinientes en los sectores regulados que reflejarían una cercanía a la potestad jurisdiccional, pero sin que esto determine confusiones o una fórmula de cercanía con las agencias norteamericanas (sólo tienen un contenido materialmente cercano a esta distinta función pública desempeñada por los jueces de la República $)^{77}$. Por último, debe indicarse que las potestades parajudiciales de los organismos reguladores se expresaron principalmente en la resolución de distintos recursos administrativos referidos tanto a la solución de reclamos de usuarios y a la solución de controversias propiamente de los prestadores ${ }^{78}$.

\section{A MODO DE CIERRE: UN EJEMPLO DE ORGANISMO REGULADOR EN LA SOMBRA}

Tal como había indicado, la evidente situación de diversidad organizativa continúa en el derecho administrativo actual, dada la cercanía de los organismos reguladores con algunas organizaciones administrativas de clara intervención regulatoria en ámbitos prestacionales, pero clasificadas legislativamente dentro de la categoría alternativa de organismos técnicos especializados (ver el artículo 31 de la LOPE).

En este acápite final intentaré sacar a la luz y explicar el fenómeno de intercambiabilidad y relativización de la supuesta lista legal cerrada de los cuatro organismos reguladores (ver el artículo 1 de la Ley n. ${ }^{\circ} 27.332$ ), que en la actualidad se presenta de manera muy potente generando más semejanzas y cercanías organizativas y funcionales entre las comparadas, pues en suma todas comparten la naturaleza de entidades instrumentales con autonomía relativa, niveles de dependencia y vinculación efectiva con el Poder Ejecutivo $^{79}$. En cualquier caso, en esta parte sólo me referiré brevemente a una de las entidades nuevas creadas al amparo del mega proceso de aseguramiento universal en salud (SUSALUD), siendo un ejemplo suficiente para mostrar la naturaleza cuasi-estatutaria del régimen organizativo regulatorio y, claro está, la posible ampliación del número actual de entidades regulatorias (más allá

\footnotetext{
77 Antonio Abruña Puyol, Delimitación jurídica de la administración pública en el ordenamiento peruano, Lima: Palestra, 2010, p. 109.

78 Jorge DANOS, op. cit., pp. 76-93.

79 Antonio Abruña Puyol, Delimitación jurídica de la administración pública en el ordenamiento peruano, Lima: Palestra, 2010 pp. 180-181.
} 
de las denominaciones institucionales y ciertas posiciones de congelamiento de la citada ordenación $)^{80}$.

En los últimos años, a partir de 2009 y con la LOPE en plena vigencia, con denominaciones más o menos paritarias, el legislador ha venido creando ciertas entidades instrumentales para desempeñar funciones casi idénticas a los organismos reguladores (potestades de limitación regulatoria, parajudiciales, reglamentarias, determinación de precios, etc.). Así primero apareció la SUTRAN en el sector del servicio del transporte terrestre; luego la SUSALUD para cuidar y velar por la asistencia sanitaria pública y privada, además del desenvolvimiento del propio proceso del aseguramiento universal en salud ${ }_{i} y_{\text {, más recientemente, }}$ la sUNEDU para regular al conjunto de universidades públicas y privadas en las prestaciones del denominado "servicio educativo universitario". En todas estas entidades los datos organizativos que presenta el legislador los concretizan con alta dosis de autonomía funcional (manifestada en aspectos administrativos, técnicos, económicos-presupuestarios, etc.), otorgamiento de personería jurídica-pública propia y potentes capacidades de gestión enmarcadas en una dependencia de corte negativo. Es más, al ser parte de los organismos públicos especializados (al igual que los reguladores), actúan siempre con la protección de la independencia funcional "con arreglo a su Ley de creación" (preceptuada en el artículo 31 de la LOPE). Todo esto podrá ser comprobado cuando se revise el régimen de la SUSALUD en las siguientes líneas.

Por otro lado, este señalado fenómeno podría encontrar causas de explicación en la falta de claridad sobre los conceptos de entidad instrumental y los propios institutos de la descentralización funcional que aparecen recogidos expresamente en la LOPE, además de la propia omisión del legislador para plantear una clasificación general de la administración pública peruana. En la actualidad, todas estas causas juntas han terminado por pulverizar la supuesta naturaleza estatutaria del ordenamiento organizativo regulatorio, presentado de manera agregada la cercanía de las sub-especies de "los Organismos públicos especializados" prevista en el artículo 31 de la LOPE (que divide a los organismos reguladores y los técnicos especializados), al menos respecto de las posiciones actuales de las tres entidades administrativas señaladas anteriormente.

En adición, también parece que las respuestas diferenciadoras por la "entidad económica" y de "mercado" de los cuatro organismos reguladores iniciales tampoco presentan datos de solución frente al fenómeno organizativo mostrado. Al respecto, como he revisado en diversas partes de este trabajo, existen actividades diversas que mezclan a operadores privados y públicos en aspectos tradicionalmente "sociales" (asistencia sanitaria, educación, etc.),

80 En la postura contraria, a pesar que no lo indican expresamente, sin embargo tampoco admiten la posible ampliación del régimen organizativo regulatorio a las nuevas superintendencias dedicadas a aspectos prestacionales, puede revisarse JORGE DANOS, op. cit., pp. 62-74; y Hebert Tassano Velaochaga, op. cit., pp. 110-118. 
pero que, sin embargo, muestran fuertes aspectos de incidencia empresarial, espacios de mercados y nociones económicas, donde vale añadir podrían existir los presupuestos y contenidos suficientes para pensar en la aparición de potestades "regulatorias" que busquen evitar daños a terceros en la actividad de los operadores, asegurar que estas actuaciones prestacionales "sociales" internalicen los costes que generan $y$, por último, sean capaces de tutelar la utilización racional de todo tipo de bienes públicos ${ }^{81}$.

Por eso, aunque se busque generar un discurso exclusivamente "económico" para explicar la posición actual y singularidad de los organismos reguladores, estimo que este es posible de ser superado largamente a partir de la creación y funcionamiento de nuevos organismos dedicados a la regulación de servicios esenciales de diversa índole (de doble iniciativa en particular), siempre que el legislador permita y los dote de condiciones organizativas y funcionales singulares (como ha sucedido con SUTRAN, SUNEDU y SUSALUD), generando -en paralelo- la reducción o limitación de la jerarquía y las potestades propias de las administraciones públicas del Estado (y del propio Gobierno).

En cualquier caso, todo lo dicho necesita ser comprobado a partir de revisar el régimen organizativo y funcionamiento de algunas de estas nuevas entidades instrumentales que se han presentado como los "reguladores no tipificados legislativamente". Así, el artículo 9 de la LMAus planteó la creación de la SUSALUD (antes llamada SUNASA) ${ }^{82}$, como una entidad administrativa adscrita al Ministerio de Salud e instaurada con fuertes dosis de "autonomía técnica, funcional, administrativa, económica y financiera", y que además, dada su catalogación legal como organismo público técnico especializado, podría sintetizar estas autonomías en la protección de la cuasi-independencia funcional "con arreglo a su Ley de creación" (ver el citado artículo 31 de la LOPE).

Al menos, de los datos funcionales presentados, es claro que surge una cercanía indudable con cualquier regulador. Es más, como veremos luego, en la esencia funcional también la SUSALUD comparte otro problema típico de estas formas organizativas singulares. Así, extrañamente el legislador, a sabiendas que la asistencia sanitaria es un sector sensible socialmente y propenso a la volatilidad e inmadurez de los políticos de turno, ha olvidado la implantación de algún mecanismo de reacción propio destinado a proteger la cuasi-independencia funcional de la SUSALUD, que le permita hacer frente a cualquier ataque o amenaza atentatoria de su contenido (piénsese en que

81 José Laguna de Paz, op. cit., p. 35.

82 Lo interesante de la creación de esta entidad instrumental es que, a fin de evitar el despilfarro de fondos públicos y la duplicidad de órdenes competenciales, la antigua SUNASA (hoy SUSALUD) se crea sobre las cenizas y restos de la desaparecida superintendencia de entidades prestadoras de salud (antigua entidad de intervención dedicada a la ordenación del sistema sanitario de los prestadores privados de salud creada al amparo del derogado Decreto Legislativo n. ${ }^{\circ} 887$ ). 
esta organización actualmente controla y supervisa instituciones o establecimientos prestadores hospitalarios y de financiamiento pertenecientes al Ministerio de Salud, gobiernos regionales y municipalidades). Por tanto, aunque hubiese sido deseable algún mecanismo instrumentalizado mediante un procedimiento administrativo o incluso uno de corte judicial (fundamentalmente de dirimencia técnico-sanitario para paliar conflictos funcionales), lo cierto es que si aparecieran problemas de este tipo, esta entidad instrumental deberá recurrir a los existentes y comunes (atacar la actuación administrativa en la jurisdicción contencioso-administrativa o acudir a la sede del TCP para proteger sus potestades públicas mediante el proceso competencial regulado por el Código Procesal Constitucional).

Por tanto, considero que otorgar autonomías sin medios para protegerlas puede ser altamente peligroso para separar y darle virtualidad a la cuasi-independencia funcional de la SUSALUD frente a los intentos de injerencia política y de dirección directa que pretendieron y hasta ahora aparecen por parte de los órganos administrativos de la administración estatal sanitaria ${ }^{83}$. Es así que, aunque pareciese una entidad administrativa alejada de los problemas de la captura del regulador, tiene una evidente cercanía con estas complicaciones, las cuales dificultan el cumplimiento estable de sus fines de interés público ${ }^{84}$.

Por otro lado, a pesar que existe una apariencia de cuidado por el elemento orgánico dentro de la LMAUS, pues se ha escogido que su máximo órgano de gobierno sea un Consejo Directivo integrado por cinco representantes (ver el artículo 18 del Decreto Legislativo N. ${ }^{\circ} 1158$ ), órgano colegiado que sería gestionado -en principio- por miembros con competencias profesionales, experiencias y capacidades directivas, con topes mínimos de temporalidad

83 Víctor HernándeZ-Mendible, Telecomunicaciones, regulación y competencia, Caracas: Editorial Jurídica Venezolana, 2009, p. 168. En ese sentido muchos de estos problemas tienen que ver con una interpretación maximalista de la dependencia de la SuSALuD con el Ministerio de Salud. Así dada su condición de organismo técnico especializado se sujeta "a los lineamientos técnicos del sector correspondiente con quien coordinan sus objetivos y estrategias" (ver el artículo 33 de la LOPE). En este punto, es claro que la cuasi-independencia funcional de esta entidad tiene un contenido de autonomía técnica inferior a la de los organismos reguladores creados durante la liberalización.

84 Los fines que deberá velar la SUNASA, según el artículo 9 de la LMAus son los siguientes: a) fortalecimiento y promoción aseguramiento universal en salud $;$ b) uso eficiente y oportuno de los fondos destinados a dicho proceso; c) la garantía y protección para asegurar la calidad, puntualidad, eficiencia y eficacia de la provisión de las prestaciones; d) la instauración de reglamentación referida a la recolección, transferencia y difusión de la información por parte de los agentes vinculados al proceso de aseguramiento universal ${ }_{i}$ e) el establecimiento, promoción y potenciación de mecanismos de conciliación y arbitraje entre los usuarios y las instituciones prestadoras y financiadoras; f) la transparencia y accesibilidad de la información en resguardo de los derechos de los asegurados; y g) otras que podrían ser planteadas por el legislador en virtud del avance de la supervisión (regulación) recaída sobre el proceso de salud pública explicado. 
debidamente demostrados y recogerían a la mayoría de actores principales involucrados en este proceso; lo cierto es que aparecen datos que demuestran flaquezas en el régimen de acceso de estos directivos.

En concordancia con lo antes indicado, el gran diferencial de la SuSALUD respecto a la cuasi-independencia orgánica mantenida por los organismos reguladores tradicionales, no está tanto en la permanencia de los integrantes en su Consejo Directivo, que podría estar asegurada de los cambios y humores políticos en virtud del auténtico régimen estatutario que impediría su libre remoción del cargo, pudiendo sólo ser afectados de recaer en las causales tasadas legislativamente (ver el artículo 22 del Decreto Legislativo N. ${ }^{\circ} 1158$ ). Por el contrario, las designaciones de estos miembros sí tienen una gran distancia con las practicadas actualmente en el régimen de las entidades regulatorias, pues no tienen ningún nivel de selectividad y se presentan como completamente ligadas a la forma típica de la designación política por parte del presidente de la República (ver el artículo 18 del Decreto Legislativo N. ${ }^{\circ} 1158$ ).

Por tanto, respecto de la cuasi-independencia orgánica de la SUSALUD, esta se presenta manifestada como en la primera etapa de los organismos reguladores durante la implantación de la liberalización, con posibilidades muy amenguadas en el acceso selectivo, competitivo y público de sus directivos, pero con dosis de protección respecto de la permanencia y retiro de estos.

Finalmente, dada la necesidad de comprobar el fenómeno de la intercambiabilidad y la relativización del listado legal de los Organismos reguladores, el dato que terminaría por comprobar la naturaleza regulatoria de la SUSALUD, estaría en los bloques de potestades habilitadas por el legislador, las cuales pueden agruparse de la siguiente manera:

i) Las potestades provenientes de la actividad de policía administrativa, siendo las que en mayor número y superior atención pueden reconocerse en la LMAus y sus modificatorias. Entre ellas podemos identificar la potestad de control sobre la ejecución contractual, la función para imponer órdenes para otorgar autorizaciones y otros títulos habilitantes necesarios para las diferentes actividades reguladas, la poderosa potestad inspectiva, la función para solicitar y exigir diversas comunicaciones obligatorias, la función de inscribir en registros administrativos actuaciones de los regulados referidas a la renovación y cancelación de su inscripción como "agentes vinculados al Aseguramiento Universal en Salud", y, finalmente, como no podía obviarse, las diversas potestades sancionadoras y de ejecución coactiva.

ii) Las potestades reglamentaria y de planificación general (esta última mediante normas e instrumentos diversos).

iii) Las potestades regulatorias no limitantes, como la promoción de la competencia $\mathrm{y}$ acceso universal de las prestacionales asistenciales, y las funciones consultivas y asistencia técnica.

iv) Otras funciones referidas a potestades parajudiciales necesarias para dirimir administrativamente conflictos entre agentes y usuarios del proceso, las 
necesarias competencias decisorias para resolver recursos dentro de su ámbito de actuación funcional, entre otras. Además cuentan con las potestades para impulsar la solución de pleitos entre los privados mediante métodos alternativos de solución de conflictos (conciliación y arbitraje instalado en un centro propio y montado institucionalmente).

Como se habrá notado, el orden competencial presentado se acerca de sobremanera a las habilitaciones de potestades de cualquier organismo regulador, al menos en las esencias y grandes tipos de estas funciones supuestamente distintas. En suma, a partir de los datos elaborados y mostrados en esta parte, me permito afirmar que la SUSALUD es una entidad administrativa con un régimen de cuasi-independencia orgánica y funcional con muchísimas dosis de cercanía a las asimiladas para los organismos reguladores tradicionalmente reconocidos en nuestro derecho; lo cual obliga a pensar que estamos al frente de un régimen unificado de estas entidades administrativas, que no necesariamente se guía por datos de singularidad o económicos, sino por los cambios propios orquestados por el legislador en la interna de la descentralización funcional (en la LOPE), siendo posible que existan muchos más reguladores, aunque con nombres distintos y ciertas variantes orgánicas o funcionales puntuales, cambios - por cierto- no sustanciales que no les hacen perder la esencia y el similar papel de aquellas importantes entidades administrativas nacidas al inicio de la liberalización en 1991.

\section{CONCLUSIONES}

A modo de cierre de este largo trabajo quisiera plantear tres conclusiones que saltan a la vista del lector:

a) En primer término, la liberalización, apoyada en la subsidiariedad horizontal, produjo no sólo cambios prestacionales y normativos en sectores, sino también supuso la creación de una nueva estructura organizativa administrativa que sirva y se acomode a ciertas características de unas aparentes "nuevas" potestades regulatorias, las cuales - desde una versión más estricta y ejecutiva- comportan una adaptación de la clásica policía administrativa y otras competencias que permiten la intervención correcta y el sostenimiento de estos sectores liberalizados.

b) En segundo lugar, debo concluir que tanto las potestades de policía regulatoria como las no directamente limitantes habilitadas a favor de los cuatro organismos reguladores iniciales y surgidos en la primera etapa de la liberalización, conformaron la esencia de la primera cláusula del Estado regulador, la cual restringió las labores prestacionales públicas, permitió la destrucción del estatismo y colaboró con devolver el protagonismo a los privados dentro de la vida social y económica del país (según lo reclamado por la subsidiariedad horizontal o social). 
c) Finalmente, la cláusula peruana del Estado regulador y la habilitación legal de un conjunto de potestades administrativas, adentró a estas nuevas entidades instrumentales en los caminos de la búsqueda del buen funcionamiento del mercado a través de la competencia y la libre concurrencia, pero sin dejar de preservar el equilibrio entre los intereses de los diferentes participantes (operadores, consumidores, usuarios, terceros interesados). Es desde esta doble perspectiva, que los organismos reguladores peruanos encontraron su utilidad y justificación en cada uno de los sectores prestacionales que sucesivamente fueron liberalizados.

\section{ABREVIATURAS}

\begin{tabular}{|l|l|}
\hline AAI & Autoridad administrativa independiente \\
AE & Agencia ejecutiva \\
BE & Banco de España \\
CMT & Comisión del Mercado de las Telecomunicaciones \\
CNC & Comisión Nacional de la Competencia \\
CNE & Comisión Nacional de Energía \\
CNMV & Comisión Nacional del Mercado Valores \\
COPRI & Comité de Promoción de la Inversión Privada \\
CP & Constitución Peruana de 1993 \\
CPT & Compañía Peruana De Teléfonos \\
CRI & Comisión Reguladora Independiente \\
CSEN & Comisión del Sistema Eléctrico Nacional \\
CSN & Consejo de Seguridad Nuclear \\
CTE & Comisión Tarifas de Energía \\
DS & Decreto Supremo \\
DL & Decreto Legislativo \\
EPS & Empresa prestadora de servicio \\
INDECOPI & Instituto Nacional de Defensa de la Competencia \\
& y de la Protección de la Propiedad Intelectual \\
OSIPTEL & Organismo Supervisor de Inversión Privada en Telecomunicaciones \\
LCE & Ley de concesiones eléctricas \\
LDEGE & Ley para asegurar el desarrollo eficiente de la generación eléctrica. \\
LGS & Ley general de salud \\
LGTT & Ley General del Transporte Terrestre \\
LPAG & Ley de Procedimiento Administrativo General \\
LMAUS & Ley marco del aseguramiento universal en salud \\
LEAASE & Ley de antimonopolio y anti-oligopolio del sector eléctrico. \\
LOPE & Ley orgánica del Poder Ejecutivo \\
LOSEN & Ley de ordenamiento del sector eléctrico nacional \\
LMOR & Ley marco de los organismos reguladores \\
LMCIP & Ley marco para el crecimiento de la inversión privada \\
LSH & Ley del sector de los hidrocarburos \\
\hline
\end{tabular}




\begin{tabular}{|l|l|}
\hline MEF & Ministerio de Economía y Finanzas \\
MIDIS & Ministerio de Desarrollo e Inclusión Social \\
MIMP & Ministerio de la Mujer y Poblaciones Vulnerables \\
MINEM & Ministerio de Energía y Minas \\
MTC & Ministerio de Transporte y Comunicaciones \\
OSINERGMIN & Organismo Supervisor de la Inversión en Energía y Minería \\
OSIPTEL & Organismo Supervisor de la Inversión en Telecomunicaciones \\
OSITRAN & Organismo Supervisor de la Inversión en Infraestructura \\
PCM & de Transporte de Uso Público \\
PROINVERSION & Presidencia del Consejo de Ministros \\
SIS & Agencia de Promoción de la Inversión Privada \\
STCP & Seguro integral de salud \\
SUNASS & Sentencia del Tribunal Constitucional Peruano \\
SUSALUD & Superintendencia Nacional de Servicios de Saneamiento \\
SUTRAN & Superintendencia Nacional de Salud \\
& Superintendencia De Transporte Terrestre de Personas \\
TCP & y Mercancías \\
TDP S.A. & Tribunal Constitucional Peruano \\
\hline
\end{tabular}

\section{BIBLIOGRAFÍA}

Abruña Puyol, Antonio. Delimitación jurídica de la administración pública en el ordenamiento peruano, Lima: Palestra, 2010.

Abruña Puyol, Antonio, y Baca Oneto, Víctor. Notas al curso de Derecho Administrativo, Piura: Facultad de Derecho de la Universidad de Piura, 2012.

Alcazar, Lorena, y Pollarolo, Pierina. "La regulación y el manejo de controversias de los sectores de telecomunicaciones y electricidad: Un análisis institucional comparativo", Documento de trabajo n.o 5, Lima: Instituto Apoyo, 2000.

Aragón Reyes, Manuel, "Del Estado intervencionista al Estado regulador", Tratado de regulación del sector eléctrico, vol. 1, Cizur Menor: Aranzandi, 2009.

Ariño Ortiz, Gaspar. "Modelos comparados: el contexto iberoamericano", Regulación económica. Lecturas escogidas, Madrid: Thomson-Reuters-Aranzadi, 2012.

Ariño Ortiz, Gaspar. "Los mercados de electricidad. El mercado interior de electricidad en Europa. Estado de la cuestión y tendencia en el umbral de 1995", Regulación Económica. Lecturas Escogidas, Madrid: Thomson-Reuters Aranzadi, 2012.

Ariño Ortiz, Gaspar. Principios de derecho público económico, Lima: Ara, 2004. 
Ariño Ortiz, Gaspar. "Sobre el significado actual de la noción de servicio público y su régimen jurídico, hacia un nuevo modelo de regulación", El nuevo servicio público, Madrid: Marcial Pons, 1997.

Ariño Ortiz, Gaspar. Economía y Estado. Crisis y reforma del sector público, Madrid: Marcial Pons, 1993.

Betancor Rodríguez, Andrés. Regulación, mito y derecho: Desmontando el mito para controlar la intervención de los reguladores económicos, Madrid: Civitas, 2010.

Caballero Ortiz, Jesús. "La descentralización funcional", Revista de Derecho Público, n. ${ }^{\circ}$ 8, Caracas: Editorial Jurídica Venezolana, 1981.

Danos Ordóñez, Jorge. "Los organismos reguladores de los servicios públicos en el Perú", Revista Peruana de Derecho de la Empresa, n. ${ }^{\circ}$ 45, Lima: Asesorandina, 2000.

Fernández García, María Yolanda. Estatuto jurídico de los servicios esenciales económicos en red, Madrid-Buenos Aires: Ciudad Argentina - INAP, 2003.

Hernández-Mendible, Víctor. Telecomunicaciones, regulación y competencia, Caracas: Editorial Jurídica Venezolana, 2009.

Parada, Ramón. Derecho administrativo I, Parte general, Madrid: Marcial Pons, 2004.

Laguna De Paz, José. Derecho administrativo económico, Navarra: Thomson-Reuters, 2016.

Lasheras, Miguel Ángel. La regulación económica de los servicios públicos, Barcelona: Editorial Ariel, 1999.

Magide Herrero, Mariano. Limites constitucionales de las administraciones independientes, Madrid: INAP, 2000.

Malaret García, Elisenda. "Administración pública y regulación económica", La autonomía municipal, administración y regulación económica, títulos académicos y profesionales, Cizur Menor-Navarra: Thonsom-Aranzadi, 2007.

Martín-Retortillo Baquer, Sebastián, Derecho administrativo económico, Madrid: La Ley, 2002.

Ramió Matas, CARles. La fortaleza institucional de las agencias reguladoras de América Latina. Especial referencia a los casos del Perú y de Republica Dominicana, Granada: UIM, 2008.

SÁnchez Morón, Miguel. Derecho administrativo. Parte general, Madrid: Tecnos, 2010.

SChmidt-Assmann, EBerhard. La teoría general del derecho administrativo como Sistema, Madrid: Marcial Pons, 2003. 
Tassano Velaochaga, Hebert. "Competencia y regulación", Revista de Derecho Pucp, n. ${ }^{\circ}$ 76, Lima: Pontificia Universidad Católica del Perú, 2016.

Tornos Mas, Joaquín. "Potestad tarifaria y política de precios", Revista de Administración Pública, n. ${ }^{\circ}$ 135, Madrid: Centro de Estudios Políticos y constitucionales, 1994.

Virgala Foruria, Eduardo. "Agencias (y agencias reguladoras) en la comunidad europea", Revista de Derecho Constitucional Europeo, n. ${ }^{\circ}$ 05, Sevilla: Instituto Andaluz de Administración Pública, 2006. 